\title{
BUOYANT AND POTENTIOMETRIC TITRATIONS OF SYNTHETIC POLYPEPTIDES III. POLY-L-LYSINE AND POLY-L-HISTIDINE IN FIVE SALT SOLUTIONS*
}

*Part II: Reference (23)

\author{
by \\ JAMES B. IFFT' ${ }^{1}$ \\ TORBEN GRAVES PEDERSEN
}

Department of Chemistry, Carlsberg Laboratory, Gamle Carlsberg Vej 10, DK-2500 Copenhagen, Valby

NORMAN FUJITA

Department of Pediatrics, Harbor General Hospital, Torrance, California U.S.A.

\section{KATHLEEN KINZIE}

1. Permanent address: Department of Chemistry, University of Redlands, Redlands, California 92373 U.S.A.

Keywords: Density gradient centrifugation, lysine, histidine, alkali halides, hydration

The buoyant titrations of poly-L-lysine and poly-L-histidine in $\mathrm{CsCl}, \mathrm{RbCl}, \mathrm{CsBr}, \mathrm{RbBr}$ and $\mathrm{KBr}$ were measured. Large differences in buoyant densities measured at low $\mathrm{pH}$ were observed for both polymers. Densities in the alkali chloride solutions are lower than for the bromides and the buoyant density increases as the size of the cation decreases in the halide series. All buoyant densities converge to a common value for each polymer at high $\mathrm{pH}$. These data are interpreted in terms of salt-pair formation at low $\mathrm{pH}$ and preferential hydrations were computed both for this charged species at low $\mathrm{pH}$ and for the neutral polymers at high $\mathrm{pH}$. The resulting data were correlated with the water activity in each buoyant solution. The variation of hydration with water activity for the charged species is found to be similar to that previously reported for bovine serum mercaptalbumin while the hydrations of the neutral polymers are found to be nearly independent of water activity. Approximate observed ionization constants were determined for each polymer in four salt solutions. 


\section{INTRODUCTION}

A number of proteins and synthetic polypeptides have been studied in density gradients generated in the analytical ultracentrifuge at sedimentation equilibrium in concentrated salt solutions $(12,15,22,23)$. These studies report the behavior of these polymers either at the isoelectric point of the proteins or the buoyant titrations, the variation of the buoyant density, $\rho_{o}$, (i.e. the density in the salt gradient at which the polymer is neutrally buoyant) with $\mathrm{pH}$. However, with one exception, all protein and polypeptide studies to date have employed $\mathrm{CsCl}$ as the gradient-forming salt. The exception is an early paper from Professor VINOGRAD's laboratory on the buoyant behavior of bovine serum mercaptalbumin at the isoelectric point in six salt solutions (17). An important result of this paper was that the preferential hydrations of the protein-salt complex, $\Gamma_{*}^{\prime}$, were found to increase exponentially with increasing water activity, $\mathbf{a}_{\mathbf{1}}$.

A strikingly different result has recently been reported by SHARP et al. (23) for ovalbumin. They analyzed data of BULL and BREESE (2) who performed equilibrium dialysis measurements with ovalbumin in a variety of salt solutions as a function of concentration. SHARP et al. concluded that $\mathrm{d} \Gamma^{\prime} / \mathrm{da} a_{1}$, where $\Gamma^{\prime}$ is the preferential hydration of salt-free protein, was almost a constant and slightly negative. In addition, they concluded that wanion and cation size and charge play significant roles in determining the extent of preferential hydration in the egg albumin three component system."

The only other density gradient studies which report hydrations of polymers are those from the laboratory of Professor HEARST. In a 1965 paper, HEARST (8) reported that the hydration of DNA increased exponentially as $a_{1}$, the water activity, increased. This is the same behavior displayed by bovine serum mercaptalbumin. However, the BMA species differed in each of the salt solutions studied because of the binding of different anions and cations.

An experimental investigation has been underway at the Carlsberg Laboratory for the past several years to measure the buoyant titrations of ovalbumin in 4 salt solutions, $\mathrm{CsCl}, \mathrm{CsBr}$, $\mathrm{RbBr}$ and $\mathrm{RbCl}$. These studies were attempted in order to measure the effect of both a cation and an anion series on the buoyant density and to derive a model therefrom for the hydration of this protein. This work is published as a companion article in this volume (18).

IFFT et al. (16) has enumerated several reasons for the study of biopolymers in a variety of solvents. Briefly these include the fact that most biopolymers are polyelectrolytes and hence interact extensively with both ions in a salt-solvent system; DANIEL (5) has studied the effects of the electric fields around various ions on $\rho_{0}$; the original method for the determination of molecular weights of polymers from density gradient experiments depends on banding the polymer in several salt systems; and the resolution of two polymers in a preparative centrifuge can be enhanced by the selection of a salt having a large density gradient proportionality constant, $\beta^{0}$, which is defined by the relation:

$$
\frac{d \rho}{d r}=\frac{\omega^{2} r}{B^{0}}
$$

An improved method for the computation of effective density gradients $(3,9)$ depends on banding the polymer and its isotopically labelled derivative in the same density gradient column in the analytical ultracentrifuge again pointing to the need for selecting different salts having high resolution capabilities. Finally, a great differential in costs exists between high purity alkali halides with $\mathrm{CsCl}$, unfortunately, nearly heading the list.

Density gradient proportionality constants for $201: 1$ electrolytes as a function of concentration and refractive index:density relations valid over the entire solubility ranges for 8 salts have been published (16). Recently, partial molar volumes, $\overline{\mathrm{V}}$, of six alkali halides have been computed (19). These $\bar{V}$ values for the salts were apportioned into $\bar{V}_{\text {ions }}$ which were tabulated along with $\bar{\nabla}$ for the solvent, water, as a function of density of the solution.

All of the above factors pointed to the need for a study of model compounds in a variety of salt solutions which represented a cation and an anion series. Thus it was determined to measure the buoyant titrations of two homopolypeptides, poly-L-lysine and poly-L-histidine in an 
alkali halide series in $\mathrm{CsCl}, \mathrm{CsBr}, \mathrm{RbCl}, \mathrm{RbBr}$ and $\mathrm{KBr}$. These two polymers were selected because their buoyant titration curves in $\mathrm{CsCl}$ (1) indicate that the buoyant titration curves in other salts could be determined without exceeding the solubility limits of the salt solutions. These alkali halides were selected because they would provide two anion series, $\mathrm{Cl}^{-}$and $\mathrm{Br}^{-}$ with constant cation and one cation series, $\mathrm{K}^{+}$, $\mathrm{Rb}^{+}, \mathrm{Cs}^{+}$with constant anion, and the densities of their saturated solutions indicated that a high enough density could be reached at both high and low $\mathrm{pH}$ 's to band both polymers.

\section{MATERIALS AND METHODS}

\subsection{Materials}

The specifications of the two polymers employed are given in Table I. The presence of $\mathrm{HBr}$ in the poly-L-Lys was ignored because the solutions were titrated to the appropriate $\mathrm{pH}$ and because of the relative concentrations of $\mathrm{Br}^{-}$versus the other ions. Polymer concentrations employed in these experiments were $0.1 \mathrm{w} / \mathrm{v}$ percent. For lysine. $\mathrm{HBr}$ of residue weight 209, this corresponds to a concentration of $0.005 \mathrm{M}$. The presence of this concentration of salt ( $\mathrm{CsBr}$ or $\mathrm{NaBr}$ depending on the buffer employed) is swamped out by the 3-4 M salt solutions employed in this study.

The cesium and rubidium salts were the 99.9\% pure grade provided by Apache Chemicals Company. The potassium bromide Suprapur grade supplied by Merck, Art. 4904 B 050172, contained a maximum impurity of $10^{-4 \%}$ of $\mathrm{Ba}$ and $\mathrm{Na}$. All buffers, $\mathrm{HCl}$, and $\mathrm{CsOH}$ used to adjust $\mathrm{pH}$ were reagent grade.
Between pH 3 and 11, the same buffers employed in an earlier study of ovalbumin (12) were used. At pH's below 3 and above 11, only $\mathrm{HCl}$ and $\mathrm{CsOH}$ were respectively used to fix the $\mathrm{pH}$.

\subsection{Methods}

Standard procedures for the conduct of density gradient runs involving proteins have been described $(11,13,14,15)$. These procedures were followed with the exceptions noted below.

A photographic method has been developed at the Carlsberg Laboratory (18). It consists of making a print at about a 10 -fold magnification employing Agfa C 90 paper and Neutol NE developer. The print is placed upside down on a light box and a tracing made in the ordinary way of the schlieren curve and all pertinent distances. This method has the advantage of providing a permanent, visual display of the schlieren image of the band for reviewing the quality and positions of the polymers' bands at a later time.

All centrifuge runs were conducted with 2 cells in an An-D or An-H rotor or with 3 or 4 cells in an An-F rotor (see ELLIS et al. (7)).

When a wide-ranging density gradient investigation such as this one is conducted, difficulties are sometimes experienced with the loss of light from the schlieren system due to the large refractive index gradients which are established. Maximum values of $\left(\omega^{2} / \beta_{e}^{0}\right) \times 10^{2}$ (where $\omega$ is the angular velocity in radians/ second, super zero denotes atmospheric pressure, and sub "e" denotes the initial solution) have been published (16) in order for there to be no loss of the polymer schlieren im-

Tabel I

Sources and Descriptions of Polymers

\begin{tabular}{|c|c|c|c|c|}
\hline Polymer & Source & $\begin{array}{l}\text { Code Number } \\
\text { Lot Number }\end{array}$ & $\begin{array}{c}\text { Molecular } \\
\text { Weight }\end{array}$ & $\begin{array}{c}\text { Degree of } \\
\text { Polymerization }\end{array}$ \\
\hline Poly-L-lysine $\cdot \mathrm{HBr}$ & Miles-Yeda & $71-120 \mathrm{D}$ & 71,000 & 340 \\
\hline Poly-L-histidine & Miles-Yeda & 71114 HS-35 & 8,750 & 64 \\
\hline
\end{tabular}


age. In order to systematize these results and to make the selection of the appropriate window an accurate and routine matter, a plot of the maximum densities for a given rotor speed, $\mathrm{rpm}$, for the three cesium halides in $0^{\circ}$ window cells was constructed. Figure 1 presents the results. When a given initial solution density is chosen, any angular velocity up to the curve for that salt may be chosen and the entire schlieren image will be recorded. Similar curves can be constructed for the $+1^{\circ}$ and $-1^{\circ}$ wedge windows using the values $(16)$ of $(1.85 \pm 0.21)$ and $(3.45 \pm$ $0.35)$ for $\left(\omega^{2} / \beta_{e}\right) \times 10^{2}$.

\section{Calculations}

\subsection{Buoyant densities}

Values for all buoyant densities were calculated using an iterative computer program written in FORTRAN for the Honeywell Bull computer at The United Breweries in Copenhagen and accessed by a Tectronic 40141 screen terminal. The published $\beta^{0}$ data as a function of density, $\rho$, were stored in one file and the slopes, $g$, of these curves were measured (18) and stored in a second file.
Values of $\beta$ and $g$ for a given density are obtained by linear interpolations. Upon receipt of a refractive index, corresponding to the initial density, the program computes, $r_{\mathfrak{e}}$, the position in the liquid column where the density equals that of the initial solution. Then the calculations move in increments of $0.0005 \mathrm{~cm}$ until $r_{o}$, the band center position, is reached. At each step, new $\beta$ values are retrieved from the data file to account for the non-constant density gradient. Buoyant densities computed in this manner were compared with values obtained by assuming $\beta$ is a constant between $\rho_{e}$ and $\rho_{0}$. Differences of up to $0.008 \mathrm{~g} / \mathrm{ml}$ in $\rho_{0}$ were noted if $\rho_{\mathrm{o}}^{\circ}-\rho_{\mathrm{e}}^{\circ}$ differend by $0.05 \mathrm{~g} / \mathrm{ml}$. Because comparisons are often necessary between buoyant densities which are quite close together (i.e. $0.005 \mathrm{~g} / \mathrm{ml}$ ), it is apparent that the iterative procedure must be used in all cases where the polymer bands more than about 1 $\mathrm{mm}$ from the isoconcentration position.

After completion of the present experimental study, an alternative method to accurately compute buoyant densities has been published (24) which will especially be useful to compute accurate $\rho_{o}$ 's when the large storage capacity required for the above program is not available.

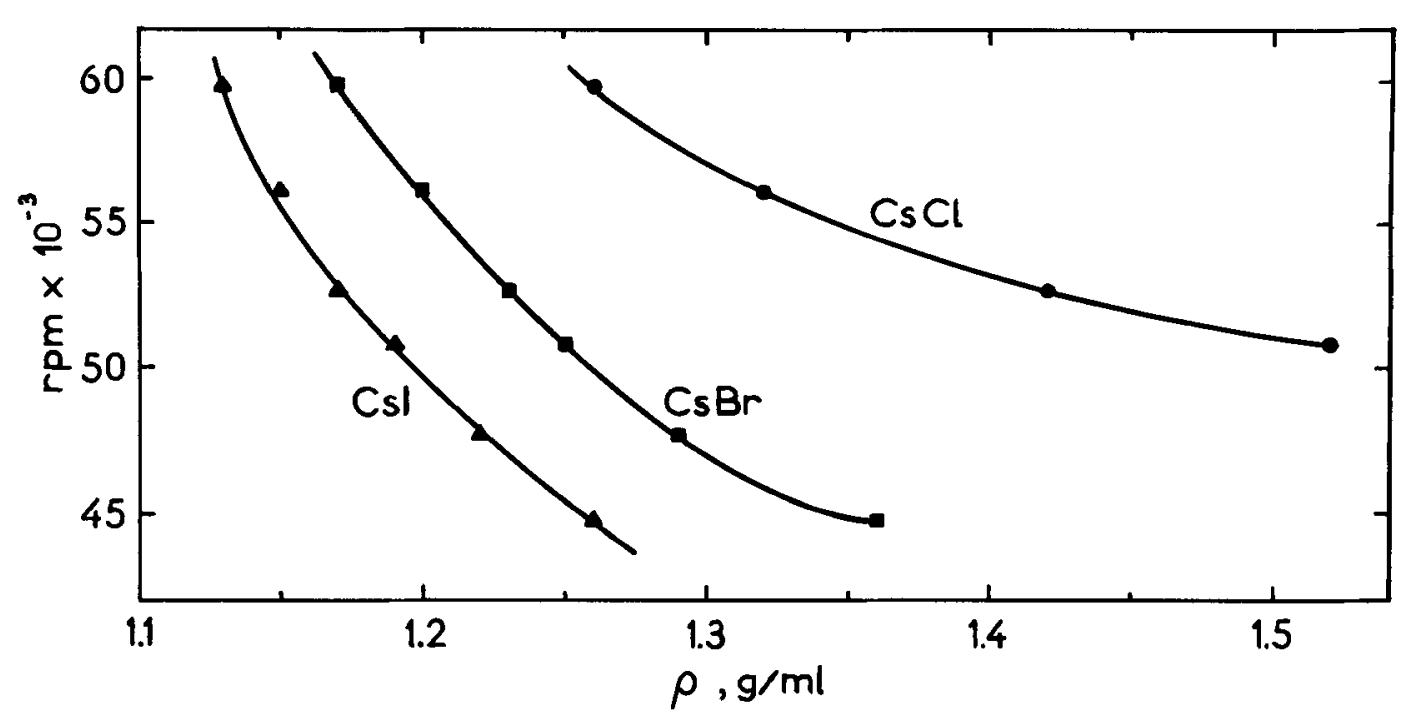

Figure 1. Selection of maximum revolutions per minute, rpm, for a given salt at a given density for $0^{\circ}$ cell windows. rpm below each curve for a given density must be selected in order for there to be no loss of the image from the schlieren optical system. 


\subsection{Partial specific volumes of potassium and bromide ions in $\mathrm{KBr}$ solutions as a function of concentration}

In order to interpret the data in $\mathrm{KBr}$, it was necessary to extend the calculations of PEDERSEN et al. (19) to include this salt, using the same data sources and computer program. The ionic radii of potassium and bromide ions were taken to be $1.33 \AA$ and $1.96 \AA$ respectively.

\subsection{Hydrations}

The determination of the preferential hydration, $\Gamma^{\prime}$, of the uncharged homopolypeptides at high $\mathrm{pH}$ is rather straightforward. The relationship between the observed buoyant density, $\rho_{0}$, the partial specific volume of the polymer, $\vec{v}_{3}$, the partial specific volume of water in the buoyant solution, $\bar{v}_{1}$, and the preferential hydration, $\Gamma^{\prime}$ in $g$ water/g polymer is given by:

$$
\rho_{0}=\frac{1+\Gamma^{\prime}}{\bar{v}_{3}+\Gamma^{\prime} \bar{v}_{1}}
$$

This relation was first derived by WILLIAMS et al. (28) and subsequently confirmed by several approaches $(6,10)$. The estimated partial specific volumes of poly-L-lysine and poly-Lhistidine were obtained from the data of $\mathrm{COHN}$ and EDSALL (4) for the neutral amino acid residues. The partial specific volumes of water was obtained from the data of PEDERSEN et al. (19) for four of the salts and from the calculations of section 3.2 for $\mathrm{KBr}$.

The calculation of the hydration of the two polypeptides at low $\mathrm{pH}$ where the $\varepsilon$-amine and the imidazole ring are charged is somewhat more complicated. IFFT and VINOGRAD (17) assumed that equation [2] could be extended by assuming that counter ions were bound to the charged groups of the polymer and that the following relation was valid:

$$
p_{0}=\frac{1+\sum_{i} z_{i}+r_{*}^{\prime}}{\bar{v}_{3}+\sum_{i} z_{i} \bar{v}_{i}+r_{*}^{\prime} \bar{v}_{1}}
$$

Here, $\bar{v}_{3}$ is redefined in terms of the protein species. The quantities $z_{i}$ and $\bar{v}_{i}$ are the weight fractions in $g \mathrm{i} / \mathrm{g}$ polymer and partial specific volumes in $\mathrm{ml} / \mathrm{g}$ of ion, $\mathrm{i}$. The summation is ex- tended over all ions bound to the polymer. This relation was used to successfully compute the anhydrous molecular weight of bovine serum mercaptalbumin and it was employed to interpret the buoyant titration curves of native (27) and a glycine amide derivative of (26) bovine serum mercaptalbumin. However, it was not until 1976 that a rigorous derivation of this relation was provided. SHARP et al. (23) derived equation [3] employing the formalism and approach of HEARST and VINOGRAD (10). Recently, an alternative derivation of this relation was obtained in conversation with Professor EISENBERG and Dr. SHARP during conversations at the Weizmann Institute of Science in Rehovoth, Israel and is given below as a further indication of the identity of the two approaches.

EISENBERG (6) expands density, rather than molality, as a function of molality and pressure:

$\mathrm{d} \rho=\left(\frac{\delta \rho}{\delta \mathrm{m}_{1}}\right)_{\mathrm{m}, \mathrm{p}} \mathrm{d \textrm {m } _ { 1 }}+\left(\frac{\delta \rho}{\delta \mathrm{m}_{3}}\right)_{\mathrm{m}, \mathrm{p}} \mathrm{d \textrm {m } _ { 3 }}+\left(\frac{\delta \rho}{\delta \mathrm{P}}\right)_{\mathrm{m}} \mathrm{dP}$

(For consistency, we convert EISENBERG's notation here to that used throughout this paper, namely $1=$ water, $2=$ salt and $3=$ polymer.)

Taking the total differential of equation [4] with respect to concentration of the polymer yields:

$$
\left(\frac{\delta \rho}{\delta m_{3}}\right)_{m}=\left(\frac{\delta \rho}{\delta m_{1}}\right)_{m, p} \frac{d m_{1}}{d m_{3}}+\left(\frac{\delta \rho}{\delta m_{3}}\right)_{m, p}+\left(\frac{\delta \rho}{\delta P}\right)_{m} \frac{d P}{d m_{3}}
$$

Expressing the total volume in terms of the respective partial specific volumes and transforming molalities to volume concentrations, we have:

$$
\left(\frac{\delta \rho}{\delta c_{3}}\right)_{\mu}=\frac{\left(1-\bar{v}_{3} \rho\right)+\xi_{2}\left(1-\bar{v}_{2} \rho\right)}{1-\left(\bar{v}_{3}+\xi_{2} \bar{v}_{2}\right) c_{3}}+\kappa \rho\left(\frac{\delta \pi}{\delta c_{3}}\right)_{\mu}
$$

In this expression, $c_{3}$ is the concentration of polymer in $\mathrm{g} / \mathrm{ml}, \pi$ is the osmotic pressure, $K$ is the isothermal compressibility $\mathrm{d} \ln \mathrm{p} / \mathrm{dP}$ at constant composition, $\mu$ is the chemical potential and constant temperature is assumed throughout. The quatity $\xi_{2}$ is an interaction parameter:

$$
\xi_{2}=\left(\frac{\delta w_{2}}{\delta w_{3}}\right)_{\mu}
$$

where the w's are weight molalities on a $g / g$ of 
water basis. Thus the units of $\boldsymbol{\xi}_{2}$ are $\mathrm{g}$ salt/g polymer.

Equation [5] can be significantly simplified by making two rather good assumptions. It is assumed that the density of the solution can be expressed as a linear expansion in $\mathrm{c}_{3}$ :

$$
\rho=\rho^{0}+\left(\delta \rho / \delta c_{3}\right)_{\mu} c_{3}
$$

where $\rho^{\circ}$ is the density of solvent (i.e. salt and water). Secondly, the osmotic pressure term can be dropped because it is negligible in comparison with the first term of equation [5].

These two assumptions permit equation [5] to be expressed in a much more recognizable form:

$$
\left(\frac{\delta \rho}{\delta c_{3}}\right)_{\mu}=\left(1-\bar{v}_{3}^{0} \rho^{0}\right)+\xi_{2}\left(1-\bar{v}_{2} \rho^{0}\right)
$$

The superscript zeros denote quantities measured in the absence of polymer, or $c_{3}=0$. The partial specific volume of salt is measured at its concentration, $c_{2}$.

Because of the symmetry of the system, equation [6] can be expressed in terms of the interaction parameter, $\xi_{i}$, of either of the two components of the solvent.

$$
\left(\frac{\delta \rho}{\delta c_{3}}\right)_{\mu}=\left(1-\bar{v}_{3}^{o} \rho\right)+\xi_{1}^{\prime}\left(1-\bar{v}_{1} \rho\right)
$$

where $\xi_{1}^{\prime}=\left(\delta w_{1}^{\prime} / \delta w_{3}^{\prime}\right)_{\mu}$ and the $\left(w^{\prime}\right)$ 's are given in $\mathrm{g} / \mathrm{g}$ of polymer. The two interaction parameters are related by:

$$
\xi_{1}^{\prime}=-\xi_{2} / w_{2}
$$

Equation [7] is identical to equation [6] of reference (20).

At the center of a protein band in a density gradient, the concentration gradient of the protein must go to zero which requires that:

$$
\left(\delta \rho / \delta c_{3}\right)_{\mu} \equiv 0
$$

At this position in the cell, the density of the solution equals $\rho_{\mathrm{o}}$, the buoyant density, by definition. (The superzero is dropped in the subsequent expression to avoid confusion with its earlier use indicating atmospheric pressure.) This identity now converts equation [7] to:

$$
\left(1-\bar{v}_{3} \rho_{0}\right)+\xi_{1}^{\prime}\left(1-\bar{v}_{1} \rho_{0}\right)=0
$$

which simplifies directly to:

$$
\rho_{\circ}=\frac{1+\xi_{1}^{\prime}}{\bar{v}_{3}+\xi_{1}^{\prime} \bar{v}_{1}}
$$

Identification of $\xi_{1}^{\prime}$ with $\Gamma_{*}^{\prime}$ and recognizing that component 3 employed here corresponds to the protein plus sufficient salt ions to yield a neutral component reveals the identity of equations [3] and [9].

The hydrations $\Gamma^{\prime}$ and $\Gamma_{*}^{\prime}$ are converted to the molar quantities by multiplication by the appropriate molecular weight ratios:

$$
\begin{aligned}
& \left.r=\Gamma^{\prime} \times \frac{(\text { MW }}{\text { residue, neutral form }}\right)^{\prime} \\
& 18.02 \\
& r_{\star}=r_{\star}^{\prime} \times \frac{\left(M W_{\text {residue, charged form }}\right)}{18.02}
\end{aligned}
$$

\subsection{Water activity}

Values for water activity, $a_{1}$, in all five salts as a function of concentration were calculated from the standard relation:

$$
\text { In } a_{1}=-\frac{v m M_{1}}{1000} \phi
$$

where $\nu$ is the number of ions per mole of salt ( 2 in all cases studied here), $\mathrm{m}$ is the molality of the salt solution, and $M_{1}$ is the molecular weight of the solvent (18.02 in the present case). Values of $\phi$, the osmotic coefficient, were obtained by plotting the data of ROBINSON and STOKES (21) and reading off $\phi$ values at the desired density.

\section{RESULTS AND DISCUSSION}

\subsection{Buoyant densities}

The buoyant densities, $\rho_{o}$, of poly-L-lysine and poly-L-histidine in the five salt solutions as a function of $\mathrm{pH}$ are plotted in Figures 2 and 3. In addition, the original data are tabulated in Tables II and III so that the reader can examine the scatter in the data and other factors pertinent to the run conditions. Observations of Figures 2 and 3 conveniently divide into three categories - the plateaus at low $\mathrm{pH}$, the nature of the transition region, and the high $\mathrm{pH}$ plateaus. 
J. B. IFFT et al.: Buoyant titrations of polypeptides

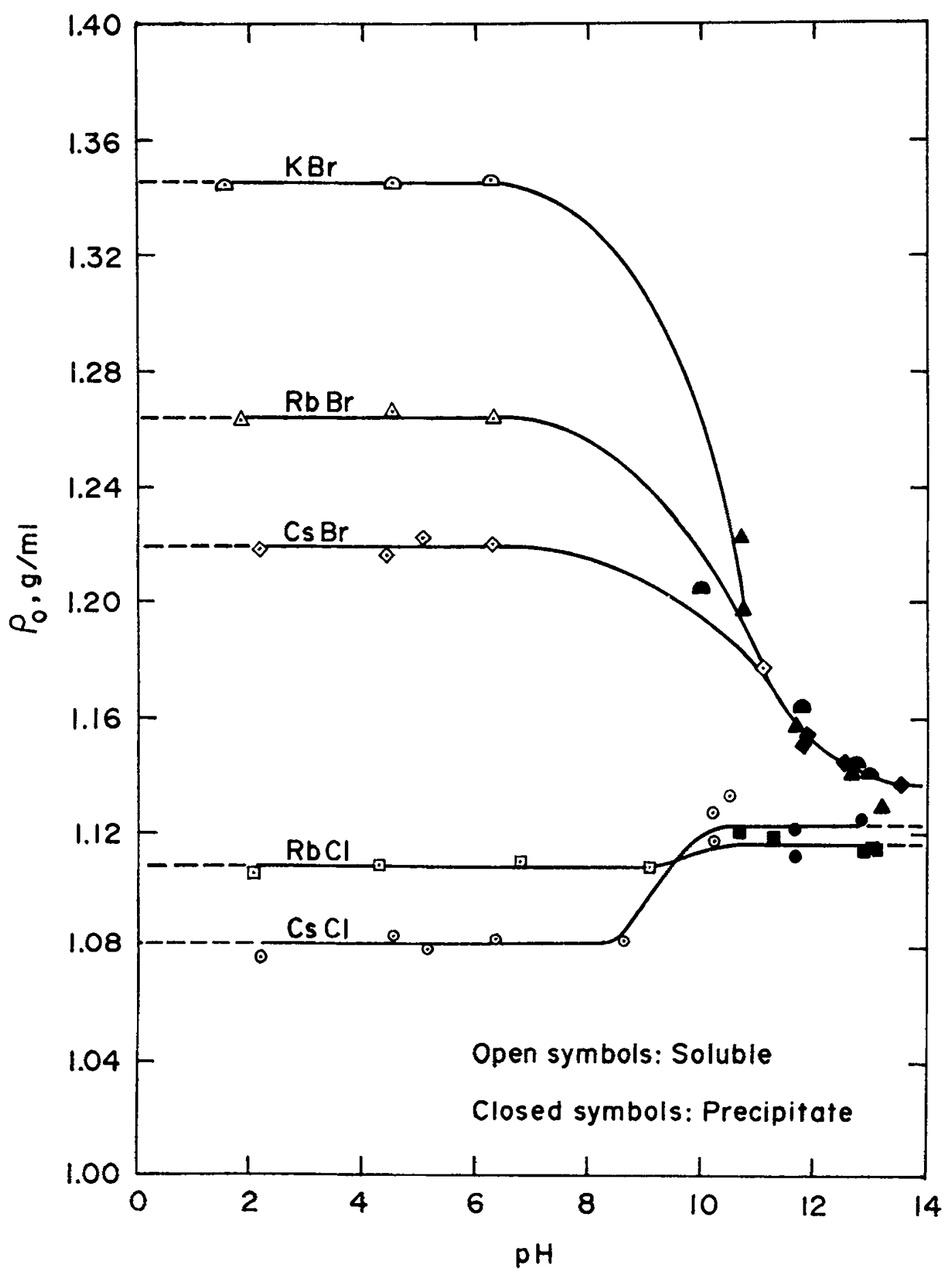

Figure 2. The buoyant titrations of poly-L-lysine in five salts at $25^{\circ} \mathrm{C}$. 
J. B. IFFT et al:: Buoyant titrations of polypeptides

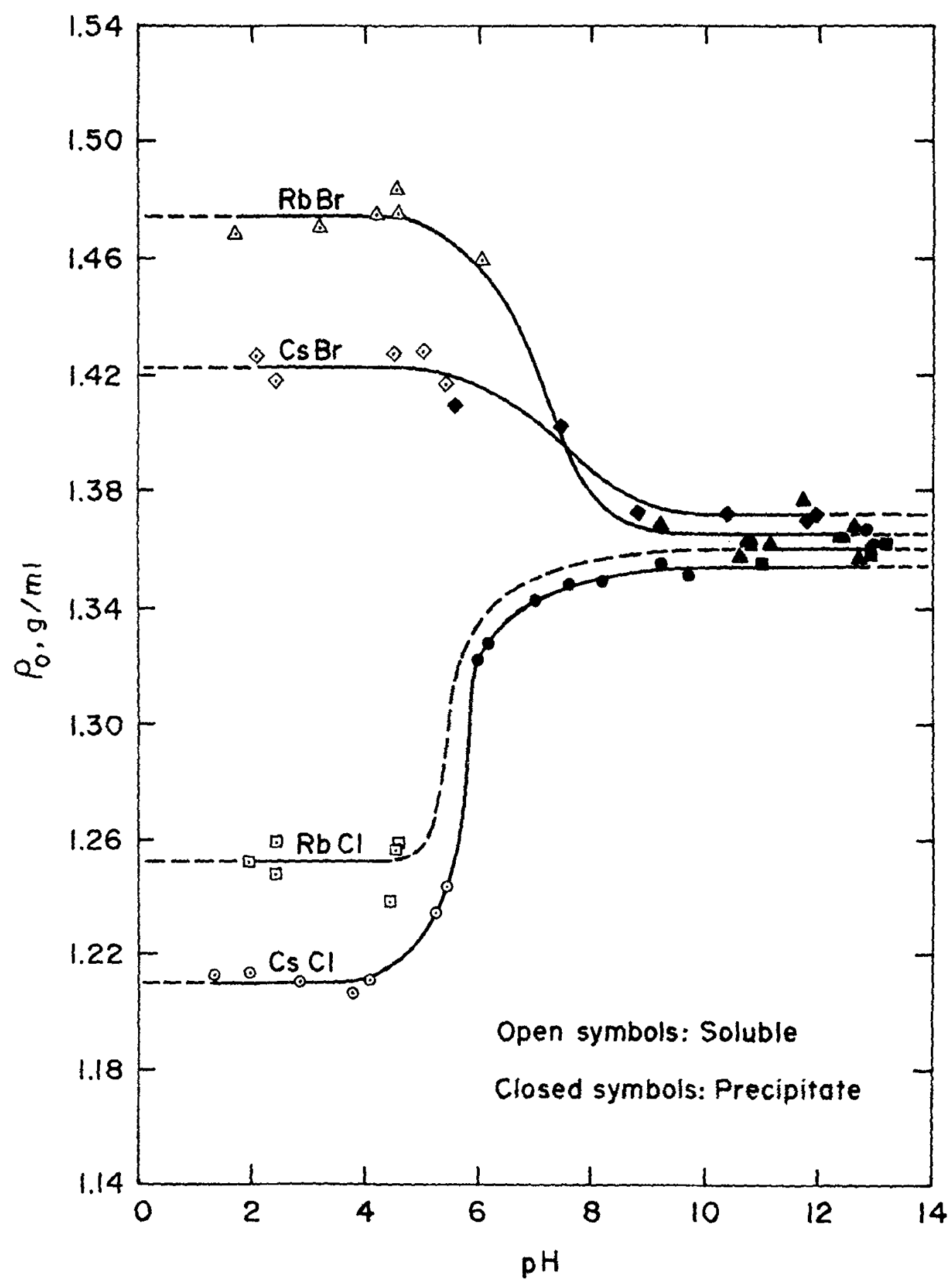

Figure 3. The buoyant titrations of poly-L-histidine in four salts at $25^{\circ} \mathrm{C}$. 
Tabel II

Original Buoyant Density Data for Poly-L-lysine

\begin{tabular}{|c|c|c|c|c|c|c|}
\hline \multirow{2}{*}{$\begin{array}{l}\text { Run } \\
\text { No. }\end{array}$} & \multirow[b]{2}{*}{$\mathrm{rpm}$} & \multirow{2}{*}{$\begin{array}{c}\rho_{0}^{0}-\rho_{\mathrm{e}}^{0} \\
\mathrm{~g} / \mathrm{ml}\end{array}$} & \multirow[b]{2}{*}{ Salt } & \multirow[b]{2}{*}{$\mathrm{pH}$} & \multicolumn{2}{|c|}{ Buoyant Densities } \\
\hline & & & & & soluble & precipitate \\
\hline$C-1231$ & 59,780 & -0.016 & $\mathrm{CsCl}$ & 2.19 & 1.076 & \\
\hline R-159 & 56,100 & -0.010 & $\mathrm{CsCl}$ & 4.57 & 1.085 & \\
\hline R-163 & 56,100 & $-0,008$ & $\mathrm{CsCl}$ & 5.12 & 1.083 & \\
\hline R-15I & 56,100 & - & $\mathrm{CsCl}$ & 6.39 & 1.085 & \\
\hline R-161 & 56,100 & -0.038 & $\mathrm{CsCl}$ & 8.63 & 1.084 & \\
\hline R-290 & 52,640 & - & $\mathrm{CsCl}$ & 9.94 & 1.121 & \\
\hline R-157 & 56,100 & $-0,023$ & $\mathrm{CsCl}$ & 10.28 & 1.125 & \\
\hline R-290 & 52,640 & - & $\mathrm{CsCl}$ & 10.49 & 1.130 & \\
\hline R-159 & 52,640 & -0.021 & $\mathrm{CsCl}$ & 11.62 & & 1.122 \\
\hline C-1231 & 59,780 & -0.019 & $\mathrm{CsCl}$ & 11.68 & & 1.112 \\
\hline$R-163$ & 56,100 & -0.001 & $\mathrm{CsCl}$ & 12.81 & & 1.120 \\
\hline C- 1232 & 52,640 & -0.007 & $\mathrm{CsBr}$ & 2.15 & 1.218 & \\
\hline $\mathrm{R}-357$ & 50,740 & +0.022 & $\mathrm{CsBr}$ & 4.41 & 1.216 & \\
\hline R-366 & 50,740 & -0.015 & $\mathrm{CsBr}$ & 5.03 & 1.222 & \\
\hline R-359 & 50,740 & +0.022 & $\mathrm{CsBr}$ & 6.28 & 1.220 & \\
\hline R-357 & 50,740 & +0.022 & $\mathrm{CsBr}$ & 11.08 & & 1.177 \\
\hline C- 1232 & 52,640 & +0.011 & $\mathrm{CsBr}$ & 11.78 & & 1.151 \\
\hline R-366 & 50,740 & -0.013 & $\mathrm{CsBr}$ & 11.84 & & 1.154 \\
\hline $\mathrm{R}-371$ & 50,740 & -0.019 & $\mathrm{CsBr}$ & 12.53 & & 1.145 \\
\hline $\mathrm{R}-357$ & 50,740 & -0.027 & $\mathrm{CsBr}$ & 13.51 & & 1.137 \\
\hline$C-1234$ & 59,780 & -0.006 & $\mathrm{RbCl}$ & 2.06 & 1.106 & \\
\hline R-395 & 59,780 & +0.001 & $\mathrm{RbCl}$ & 4.29 & 1.109 & \\
\hline R-397 & 50,740 & -0.001 & $\mathrm{RbCl}$ & 6.78 & 1.110 & \\
\hline R-401 & 59,780 & -0.013 & $\mathrm{RbCl}$ & 9.09 & 1.108 & \\
\hline R-395 & 59,780 & -0.014 & $\mathrm{RbCl}$ & 10.69 & & 1.120 \\
\hline$R-399$ & 59,780 & -0.012 & $\mathrm{RbCl}$ & 11.29 & & 1.126 \\
\hline C- 1234 & 59,780 & -0.012 & $\mathrm{RbCl}$ & 12.91 & & 1.114 \\
\hline R-399 & 59,780 & -0.023 & $\mathrm{RbCl}$ & 13.05 & & 1.115 \\
\hline $\mathrm{R}-401$ & 59,780 & -0.023 & $\mathrm{RbCl}$ & 13.14 & & 1.115 \\
\hline C- 1235 & 59,780 & -0.020 & $\mathrm{RbBr}$ & 1.82 & 1.263 & \\
\hline R-367 & 50,740 & -0.008 & $\mathrm{RbBr}$ & 4.49 & 1.266 & \\
\hline$R-360$ & 50,740 & +0.034 & $\mathrm{RbBr}$ & 6.30 & 1.264 & \\
\hline R-403 & 50,740 & +0.012 & $\mathrm{RbBr}$ & 10.68 & & 1.222 \\
\hline R-376 & 50,740 & +0.003 & $\mathrm{RbBr}$ & 10.73 & & 1.197 \\
\hline R-403 & 50,740 & +0.001 & $\mathrm{RbBr}$ & 11.70 & & 1.157 \\
\hline R-372 & 50,740 & -0.014 & $\mathrm{RbBr}$ & 12.68 & & 1.141 \\
\hline C-1235 & 59,780 & -0.036 & $\mathrm{RbBr}$ & 13.19 & & 1.129 \\
\hline C- 1236 & 59,780 & -0.005 & $\mathrm{KBr}$ & 1.55 & 1.344 & \\
\hline R-380 & 50,740 & +0.033 & $\mathrm{KBr}$ & 4.51 & 1.345 & \\
\hline$R \cdot 388$ & 59,780 & +0.022 & $\mathrm{KBr}$ & 6.25 & 1.346 & \\
\hline R-377 & 50,740 & +0.028 & $\mathrm{KBr}$ & 10.00 & & 1.205 \\
\hline$R-388$ & 59,780 & -0.019 & $\mathrm{KBr}$ & 11.78 & & 1.164 \\
\hline C- 1236 & 59,780 & -0.008 & $\mathrm{KBr}$ & 12.75 & & 1.144 \\
\hline R-375 & 50,740 & -0.001 & $\mathrm{KBr}$ & 12,96 & & 1.141 \\
\hline
\end{tabular}


Table III

Original Buoyant Density Data for Poly-L-histidine

\begin{tabular}{|c|c|c|c|c|c|c|}
\hline $\begin{array}{l}\text { Run } \\
\text { No. }\end{array}$ & rpm & $\begin{array}{l}\rho_{\mathrm{O}}^{\mathrm{O}}-\rho_{\mathrm{e}}^{\mathrm{O}} \\
\mathrm{g} / \mathrm{ml}\end{array}$ & Salt & $\mathrm{pH}$ & \multicolumn{2}{|c|}{ Buoyant Densities } \\
\hline $\mathrm{R}-172$ & 59,780 & -0.021 & $\mathrm{CsCl}$ & 1.32 & 1.215 & \\
\hline C-1237 & 59,780 & -0.021 & $\mathrm{CsCl}$ & 1.96 & 1.213 & \\
\hline R-171 & 59,780 & -0.032 & $\mathrm{CsCl}$ & 2.87 & 1.211 & \\
\hline R-173 & 59,780 & -0.043 & $\mathrm{CsCl}$ & 3.61 & 1.207 & \\
\hline R-172 & 59,780 & -0.023 & $\mathrm{CsCl}$ & 4.11 & 1.213 & \\
\hline R-225 & 52,640 & -0.023 & $\mathrm{CsCl}$ & 5.28 & 1.235 & \\
\hline R-225 & 52,640 & -0.025 & $\mathrm{CsCl}$ & 5.46 & 1.244 & \\
\hline R-209 & 52,640 & +0.069 & $\mathrm{CsCl}$ & 5.96 & & 1.323 \\
\hline R-209 & 52,640 & +0.018 & $\mathrm{CsCl}$ & 6.15 & & 1.332 \\
\hline R-209 & 52,640 & +0.021 & $\mathrm{CsCl}$ & 6.97 & & 1.346 \\
\hline R-180 & 56,100 & +0.017 & $\mathrm{CsCl}$ & 7.57 & & 1.350 \\
\hline R-180 & 56,100 & -0.068 & $\mathrm{CsCl}$ & 8.13 & & 1.349 \\
\hline R-333 & 50,740 & 0 & $\mathrm{CsCl}$ & 9.21 & & 1.355 \\
\hline R-336 & 50,740 & - & $\mathrm{CsCl}$ & 9.67 & & 1.352 \\
\hline C- 1237 & 59,780 & -0.014 & $\mathrm{CsCl}$ & 12.79 & & 1.367 \\
\hline$R-341$ & 50,740 & -0.015 & $\mathrm{CsBr}$ & 2.08 & 1.426 & \\
\hline$C-1238$ & 59,780 & -0.031 & $\mathrm{CsBr}$ & 2.43 & 1.418 & \\
\hline R-347 & 50,740 & -0.017 & $\mathrm{CsBr}$ & 4.49 & 1.427 & \\
\hline R-343 & 50,740 & -0.017 & $\mathrm{CsBr}$ & 5.02 & 1.428 & \\
\hline R-339 & 50,740 & -0.010 & $\mathrm{CsBr}$ & 5.43 & 1.417 & \\
\hline R-331 & 44,770 & +0.003 & $\mathrm{CsBr}$ & 5.59 & & 1.409 \\
\hline R-337 & 50,740 & +0.017 & $\mathrm{CsBr}$ & 7.46 & & 1.402 \\
\hline R-341 & 50,740 & -0.013 & $\mathrm{CsBr}$ & 8.81 & & 1.372 \\
\hline R-327 & 50,740 & +0.068 & $\mathrm{CsBr}$ & 10.39 & & 1.372 \\
\hline $\mathrm{C}-1238$ & 59,780 & -0.023 & $\mathrm{CsBr}$ & 11.78 & & 1.370 \\
\hline $\mathrm{R}-343$ & 50,740 & +0.002 & $\mathrm{CsBr}$ & 11.93 & & 1.372 \\
\hline$C-1239$ & 59,780 & +0.004 & $\mathrm{RbCl}$ & 1.94 & 1.252 & \\
\hline R-369 & 50,740 & +0.013 & $\mathrm{RbCl}$ & 2.40 & 1.247 & \\
\hline R-380 & 50,740 & -0.005 & $\mathrm{RbCl}$ & 2.43 & 1.259 & \\
\hline R-364 & 50,740 & +0.013 & $\mathrm{RbCl}$ & 4.46 & 1.238 & \\
\hline R-374 & 50,740 & +0.002 & $\mathrm{RbCl}$ & 4.53 & 1.256 & \\
\hline R-377 & 50,740 & +0.001 & $\mathrm{RbCl}$ & 4.54 & 1.258 & \\
\hline R-364 & 50,740 & -0.003 & $\mathrm{RbCl}$ & 10.97 & & 1.355 \\
\hline$R=369$ & 50,740 & -0.006 & $\mathrm{RbCl}$ & 12.90 & & 1.358 \\
\hline$C-1239$ & 59,780 & -0.012 & $\mathrm{RbCl}$ & 13.18 & & 1.362 \\
\hline C-1240 & 59,780 & -0.010 & $\mathrm{RbBr}$ & 1.70 & 1.468 & \\
\hline R-355 & 50,740 & +0.005 & $\mathrm{RbBr}$ & 3.18 & 1.470 & \\
\hline $\mathrm{R}-373$ & 59,780 & -0.012 & $\mathrm{RbBr}$ & 4.19 & 1.475 & \\
\hline R-349 & 50,740 & +0.014 & $\mathrm{RbBr}$ & 4.54 & 1.483 & \\
\hline R-349 & 50,740 & +0.016 & $\mathrm{RbBr}$ & 4.58 & 1.475 & \\
\hline R-341 & 50,740 & -0.024 & $\mathrm{RbBr}$ & 6.06 & 1.459 & \\
\hline R-336 & 50,740 & -0.005 & $\mathrm{RbBr}$ & 9.23 & & 1.369 \\
\hline R-352 & 50,740 & -0.010 & $\mathrm{RbBr}$ & 10.61 & & 1.357 \\
\hline R-347 & 50,740 & -0.023 & $\mathrm{RbBr}$ & 11.14 & & 1.361 \\
\hline R-349 & 50,740 & +0.002 & $\mathrm{RbBr}$ & 11.69 & & 1.377 \\
\hline R-350 & 44,770 & +0.047 & $\mathrm{RbBr}$ & 12.61 & & 1.367 \\
\hline$C-1240$ & 59,780 & -0.017 & $\mathrm{RbBr}$ & 12.69 & & 1.357 \\
\hline R-352 & 50,740 & +0.025 & $\mathrm{KBr}$ & 10.78 & & 1.365 \\
\hline C- 1241 & 44,770 & -0.001 & $\mathrm{KBr}$ & 12.39 & & 1.364 \\
\hline R-369 & 50,740 & +0.001 & $\mathrm{KBr}$ & 12.95 & & 1.361 \\
\hline
\end{tabular}


Table IV

Buoyant Densities, Partial Specific Volumes of Anions and Water, Water Activities and Hydrations for Poly-L -lysine and Poly-L-histidine at Low pH

\begin{tabular}{|c|c|c|c|c|c|c|}
\hline Salt & $\rho_{o}$ & $\overline{\mathbf{v}}_{\mathbf{X}}-$ & $\bar{v}_{1}$ & al & $\begin{array}{c}\mid \Gamma_{*}^{\prime} \\
\mathrm{g} \mathrm{H}_{2} \mathrm{O} / \\
\mathrm{g} \text { polymer }\end{array}$ & $\begin{array}{c}\qquad \Gamma_{*} \\
\text { mole } \mathrm{H}_{2} \mathrm{O} / \\
\text { mole residue }\end{array}$ \\
\hline & \multicolumn{6}{|c|}{ poly-L-lysine } \\
\hline $\mathrm{CsCl}$ & 1.081 & 0.6485 & 1.0025 & 0.980 & 2.35 & 16.9 \\
\hline $\mathrm{RbCl}$ & 1.108 & 0.6480 & 1.0014 & 0.958 & 1.55 & 11.1 \\
\hline $\mathrm{CsBr}$ & 1.219 & 0.3760 & 1.0013 & 0.956 & 1.53 & 10.9 \\
\hline $\mathrm{RbBr}$ & 1.264 & 0.3758 & 0.9994 & 0.926 & 1.10 & 7.9 \\
\hline \multirow[t]{2}{*}{$\mathrm{KBr}$} & 1.345 & 0.3762 & 0.9940 & 0.828 & 0.61 & 4.3 \\
\hline & \multicolumn{6}{|c|}{ poly-L-histidine } \\
\hline $\mathrm{CsCl}$ & 1.210 & 0.6731 & 1.0004 & 0.945 & 1.15 & 8.9 \\
\hline $\mathrm{RbCl}$ & 1.252 & 0.6835 & 0.9968 & 0.894 & 0.82 & 6.3 \\
\hline $\mathrm{CsBr}$ & 1.423 & 0.3851 & 0.9987 & 0.911 & 0.75 & 5.7 \\
\hline $\mathrm{RbBr}$ & 1.474 & 0.3866 & 0.9954 & 0.856 & 0.58 & 4.4 \\
\hline
\end{tabular}

\subsubsection{Low pH}

The side chains of both of these basic polypeptides at $\mathrm{pH}$ 's $<7$ have tetravalent nitrogen atoms with one positive charge. We therefore assume that a salt pair:

$$
\supseteqq \stackrel{\oplus}{\mathrm{N}}-\mathrm{H} \dot{\mathrm{x}}
$$

exists on each side chain with the $\mathrm{X}^{-}$being either chloride or bromide. Thus, one result which may have been expected was that all salts with the same halide would band at the same density. This is clearly not the case as is evident in each of the two pairs of $\mathrm{Cs} / \mathrm{Rb}$ salts and also in the $\mathrm{Cs} / \mathrm{Rb} / \mathrm{K}$ series. In each case, the buoyant densities increase in the series: $\mathrm{Cs}^{+}<\mathrm{Rb}^{+}<$ $\mathrm{K}^{+}$. Even if the cations were bound in some way to the polymer, the densities of the cations cannot explain this series because the atomic weight divided by the partial molar volumes of the cation at the buoyant density gives some measure of the density of the bound ion and these densities are in the order: $\mathrm{Cs}^{+}>\mathrm{Rb}^{+}>$ $\mathrm{K}^{+}$

A surprising observation of this study deals with the partial specific volumes, $\bar{v}_{X^{-}}$, of the bound anions.

At the buoyant densities listed in Table IV, the $\bar{v}$ 's of the halide ions may be obtained by dividing the partial molar volumes, $\bar{\nabla}_{X^{-}}$, of PEDERSEN et al. (19) by the atomic weight of the anion. The wholly unexpected result is that the $\bar{v}$ 's of $\mathrm{Cl}^{-}$and $\bar{v}$ 's of $\mathrm{Br}^{-}$are identical in the lysine case and, though not identical, closely similar for the histidine polymer. This is most surprising in view of the rather different densities at which the polymers band and the widely divergent partial molar volumes for $\mathrm{Br}^{-}$ and $\mathrm{Cl}^{-}$in the $\mathrm{Cs}^{+}$and $\mathrm{Rb}^{+}$salts as displayed in Figure 3 of PEDERSEN et al. (19).

Another result which was anticipated was that the buoyant densities of the polymers in $\mathrm{Br}^{-}$solutions would be greater than in $\mathrm{Cl}^{-}$ solution for the same cation because the approximate densities of these anions (as measured by $\mathrm{MW}_{\mathrm{X}^{-}} / \overline{\mathrm{V}}_{\left.\mathrm{X}^{-}\right)}$) are $2.66 \mathrm{~g} / \mathrm{ml}$ and 1.54 $\mathrm{g} / \mathrm{ml}$ respectively. The data observed in Figures 2 and 3 match this prediction in each case.

\subsubsection{Transition $p H$ range}

The buoyant titrations reported to date for native and chemically modified proteins $(7,12$, $15,22,26,27)$ and for polypeptides $(1,23)$ have all been conducted in $\mathrm{CsCl}$. In every case, the 
buoyant density increases with increasing $\mathrm{pH}$. The data presented in Figures 2 and 3 (as well as the buoyant titrations of PEDERSEN (18) in the accompanying article) are the first buoyant titrations in which the reverse has been observed. In all cases observed here, the $\rho_{0}$ of the polypeptide increases as the $\mathrm{pH}$ is raised in the chloride solutions and decreases in the bromide salts. Thus the two reactions:

$$
\begin{aligned}
& \geqslant \stackrel{\oplus}{\mathrm{N}}-\mathrm{H} \mathrm{Cl}^{\ominus}+\mathrm{OH}^{\ominus} \rightarrow \geqslant \mathrm{N}+\mathrm{Cl}^{\ominus}+\mathrm{HOH} \\
& \geqslant \stackrel{\oplus}{\mathrm{N}}-\mathrm{H} \mathrm{Br}+\mathrm{OH}^{\ominus} \rightarrow \geqslant \mathrm{N}+\mathrm{Br}^{\ominus}+\mathrm{HOH}
\end{aligned}
$$

have opposite effects upon the densities. The reasons for this are more fully explored when preferential hydrations are discussed in section 4.3. below.

The major purpose of this study was to examine the low and high $\mathrm{pH}$ behavior of these two polypeptides in a variety of solvents. However, in order to delineate these values, in most cases some data were obtained in the transition regions so that at least the approximate shapes of the curves in these regions could be determined. Therefore, in all cases except poly$\mathrm{L}-\mathrm{H}$ is in $\mathrm{KBr}$ (where the $\rho_{\mathrm{o}}$ at low $\mathrm{pH}$ exceeded the solubility of the salt) and in $\mathrm{RbCl}$ (where no data in the intermediate region were obtained), approximate observed dissociation constants
Table V

Apparent Dissociation Constants of Poly-L-lysine and Poly-L-histidine in Various Buoyant Salt Solutions at $25^{\circ} \mathrm{C}$

\begin{tabular}{lcc}
\hline Poly-L-lysine & Salt & $\mathbf{p K}_{\mathbf{0 b s}}$ \\
& $\mathrm{CsCl}$ & 9.2 \\
& $\mathrm{RbCl}$ & 9.8 \\
& $\mathrm{CsBr}$ & 10.9 \\
& $\mathrm{RbBr}$ & 10.5 \\
& $\mathrm{KBr}$ & 10.3 \\
\hline Poly-L-histidine & $\mathrm{CsCl}$ & 5.8 \\
& $\mathrm{CsBr}$ & 7.4 \\
& $\mathrm{RbBr}$ & 7.1 \\
\hline
\end{tabular}

for the residues could be obtained. Even with a rather large uncertainty, the data presented in Table $\mathrm{V}$ indicate that the $\mathrm{pK}_{\mathrm{obs}}$ values are about one unit higher in the bromide salts than in the chloride salts.

\subsubsection{High $p H$}

In all salt solutions, each polymer has the same structure and as a first approximation displays the same buoyant density. However, as discussed below, for any particular solution density, each solution would require a different

\section{Tabel VI}

Buoyant Densities, Partial Specific Volumes of Water, Water Activities and Hydrations for Poly-L -lysine and Poly-

\begin{tabular}{|c|c|c|c|c|c|}
\hline Sait & po & $\overline{\mathbf{v}}_{1}$ & $a_{1}$ & $\begin{array}{c}\Gamma^{\prime} \\
\mathrm{g} \mathrm{H}_{2} \mathrm{O} / \\
\text { g polymer }\end{array}$ & $\begin{array}{c}\boldsymbol{\Gamma} \\
\text { moles } \mathrm{H}_{2} \mathrm{O} / \\
\text { mole residue }\end{array}$ \\
\hline \multicolumn{6}{|c|}{ poly-L-lysine } \\
\hline $\mathrm{CsCl}$ & 1.123 & 1.0020 & 0.969 & 0.64 & 4.6 \\
\hline $\mathrm{RbCl}$ & 1.116 & 1.0011 & 0.954 & 0.73 & 5.2 \\
\hline $\mathrm{CsBr}$ & 1.136 & 1.0022 & 0.973 & 0.50 & 3.6 \\
\hline $\mathrm{RbBr}$ & 1.136 & 1.0017 & 0.963 & 0.51 & 3.6 \\
\hline $\mathrm{KBr}$ & 1.136 & 1.0009 & 0.942 & 0.51 & 3.6 \\
\hline \multicolumn{6}{|c|}{ poly-L-histidine } \\
\hline $\mathrm{CsCl}$ & 1.354 & 0.9974 & 0.901 & 0.28 & 2.2 \\
\hline $\mathrm{RbCl}$ & 1.360 & 0.9926 & 0.837 & 0.27 & 2.1 \\
\hline $\mathrm{CsBr}$ & 1.372 & 0.9994 & 0.923 & 0.24 & 1.8 \\
\hline $\mathrm{RbBr}$ & 1.365 & 0.9978 & 0.895 & 0.26 & 1.9 \\
\hline $\mathrm{KBr}$ & 1.363 & 0.9931 & 0.815 & 0.27 & 2.0 \\
\hline
\end{tabular}
L-histidine at High pH 
molality which in turn would produce different water activities. Because of earlier findings ( 10 , 17) on the effect of water activity on hydration and hence on buoyant density, it was anticipated that the buoyant densities would not converge at high $\mathrm{pH}$.

The data for poly-L-lysine in the chloride salts display considerable scatter and even though the two $\rho_{o}$ 's differ by $0.007 \mathrm{~g} / \mathrm{ml}$, it is quite possible that these $\rho_{0}$ 's are identical. The $\mathrm{pK}_{\mathrm{obs}}$ 's in the bromide salts are so high that it is not clear that the buoyant densities have stopped falling even at $\mathrm{pH} 13$. It does appear however that all values are converging to a common value of about 1.136 inasmuch as only one line can be drawn through the last 11 points.

All buoyant titration curves for poly-Lhistidine level off to approximately the same value at $\mathrm{pH} 10-13, \rho_{\mathrm{o}}=1.363 \mathrm{~g} / \mathrm{ml}$.

These data are summarized in Table VI. The buoyant densities listed represent the average of the highest $\mathrm{pH}$ buoyant density values where no further changes in $\rho_{0}$ could be observed. These values correspond to the horizontal lines drawn in Figures 2 and 3.

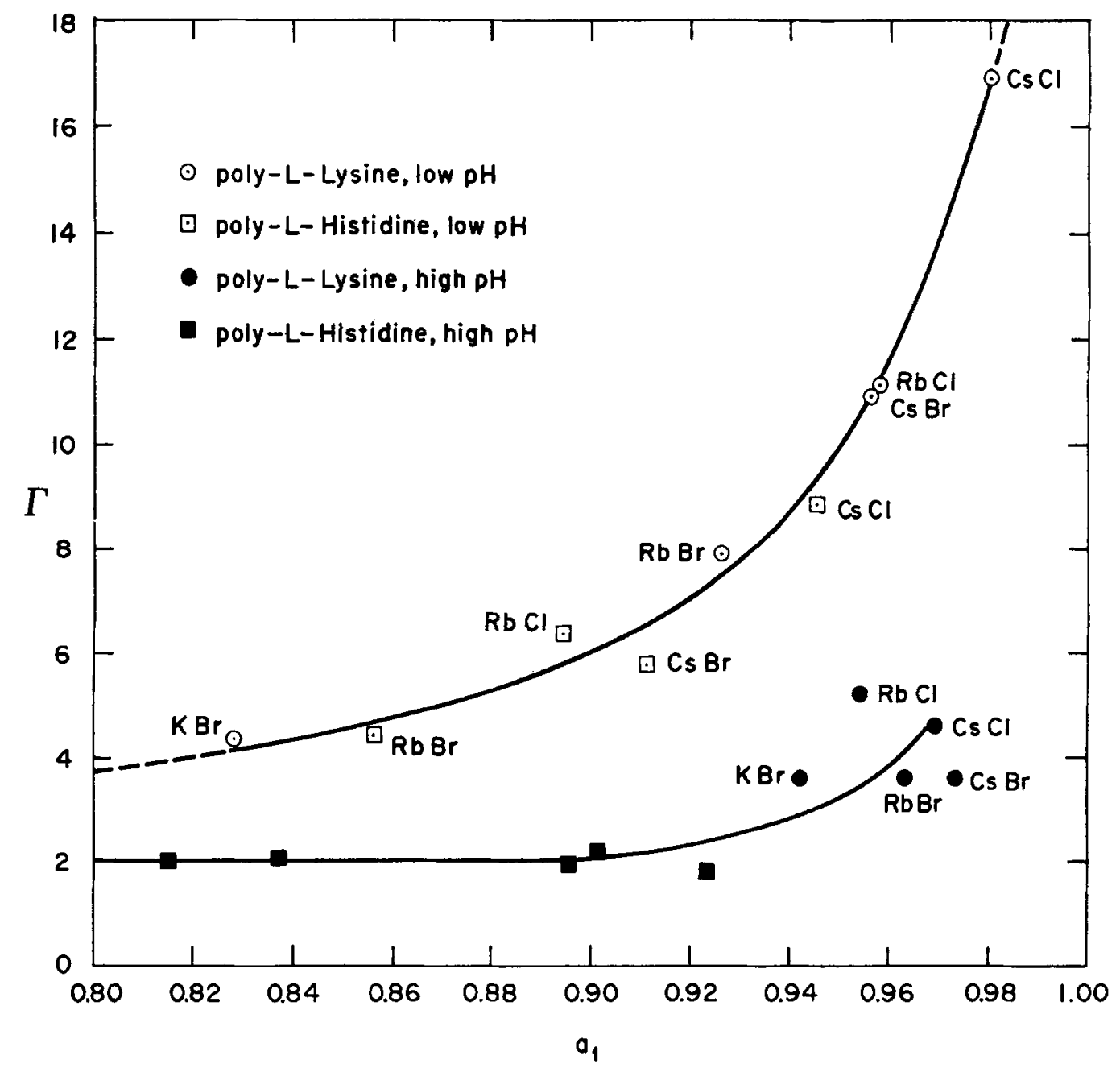

Figure 4 . The preferential hydrations, $\Gamma$ and $\Gamma_{*}$, of the uncharged and charged forms of poly-L -lysine and polyL-histidine as a function of water activity, $a_{\mathbf{l}}$. 


\subsection{Partial molar volumes of potassium and bromide ions.}

The values obtained by the method of Pedersen et al. (19) are tabulated in Table VII. As might be expected from the position of potassium in the Periodic Table, the molar volumes of $\mathrm{K}^{+}$are much lower than any of the ions previously studied. It was of interest to note the magnitude of the $\mathrm{Br}^{-}$values and to compare them with the values presented in Figure 3 of PEDERSEN et al. (19). Although the data extend only up to $\rho=1.31 \mathrm{~g} / \mathrm{ml}$, a reasonable extrapolation of the data showed that this curve for $\overline{\mathrm{B}}_{\mathrm{Br}}$-would be expected to pass through the intersection of the curves for $\mathrm{CsBr}$ and $\mathrm{RbBr}$ producing the unique triple point noted earlier in the data for $\bar{V}_{\mathrm{Rb}}+$ and $\overline{\mathrm{V}}_{\mathrm{Cs}^{+}}$.

\subsection{Hydrations and water activities}

The preferential hydrations, moles $\mathrm{H}_{2} \mathrm{O} /$ mole residue $\Gamma$ and $\Gamma_{*}$, were computed for the protonated and deprotonated forms of the two polypeptides employing equations [2], [10] and [3], [11] respectively. The results are tabulated in Tables IV and VI and graphically displayed in Figure 4.

As discussed above, the results at high $\mathrm{pH}$ indicate that the hydration of these two polymers in the neutral form is almost invariant with water activity. There is sufficient scatter in the poly-L-lysine data that it appears that both molecules are hydrated to the extent of 2 to 3 water molecules per residue and that this hydration does not vary throughout the water activity range examined. Furthermore, because of the uncertainty in the COHN and EDSALL $\bar{v}$ values, the possibility exists that a small change in the $\bar{v}$ values would result in zero values for $r$. This result would be in accord with that of PEDERSEN (18) that the neutral residues of ovalbumin display no preferential hydration.

The earlier results for the different neutral species of bovine serum mercaptalbumin (17) and for DNA (8) indicate that the preferential hydration increases monotonically with water activity. Similarly, PEDERSEN et al. (18) in the following article in this journal have observed an increase in the hydration of the "charge-ion complexes" of ovalbumin as a function of water activity. However, the analysis by SHARP et al. (25) of the data of BULL and BREESE (2) indicates no change in the hydration of egg albumin with $a_{1}$.

The preferential hydrations obtained in this investigation for poly-L-lysine and poly-Lhistidine in their charged forms at low $\mathrm{pH}$ are displayed in the upper curve of Figure 4. They represent the most interesting result of this study. Not only do the preferential hydrations of both polymers increase with increasing $a_{1}$, the data for both polypeptides fall on the same curve. This is rather surprising in view of the quite different nature of the side chains of the two residues. It will be of considerable interest to investigate other homopolypeptides in the future and determine whether all basic amino acid residues share this property and whether the acidic residues can be similarly grouped.

\section{ACKNOWLEDGEMENTS}

The authors are pleased to acknowledge the stimulation of Professor MARTIN OTTESEN in asking helpful questions during the collection of these data and the preparation of this manuscript. This work was supported in part by Research Grant No. GM-18871 from the National Institute of General Medical Sciences of the United States Public Health Service. J. B. I. is indebted to the Carlsberg Laboratory for financial support and to the University of Redlands, Redlands, California for providing a sabbatical leave for the 1976-1977 academic year when a portion of this work was completed. T. G. P. gratefully acknowledges salary and travel support from the Carlsberg Foundation and the U. S. National Institutes of Health. N. F. was supported for two summers by an Undergraduate Research Participation grant from the National-Science Foundation of the United States. 


\section{REFERENCES}

1. Almassy, R., J. S. V. ZiL, L. G. Lum \& J. B. IfFT: Buoyant and potentiometric titrations of synthetic polypeptides. I. Six ionizable homopolypeptides in $\mathrm{CsCl}$ solutions. Biopolymers 12, 2713-2729 (1973)

2. BULL, H. J. \& K. BreEsE: Binding of water and electrolytes to proteins. An equilibrium dialysis study. Biopolymers 15, 1573-1583 (1976)

3. Cohen, G. \& H. Eisenberg: Deoxyribonucleate solutions: Sedimentation in a density gradient, partial specific volumes, density and refractive index increments, and preferential interactions. Biopolymers 6, 1077-1 100 (1968)

4. Cohn, E. J. \& J. T. Edsall: Density and apparent specific volume of proteins. In: Proteins, Amino Acids and Peptides as Ions and Dipolar Ions. Chapter 16, p. 372. Reinhold (New York) (1943)

5. Danjel, E.: Equilibrium sedimentation of a polyelectrolyte in a density gradients of a lowmolecular weight electrolyte. I. DNA in CsCl. Biopolymers 7, 359-377 (1969)

6. EISENBERG, H.: Biological macromolecules and polyelectrolytes in solution. Chapter 2, pp. 54-59. Clarendon Press (Oxford) (1976)

7. Ellis, D. A., V. Coffman \& J. B. IfFT: The buoyant titration of native and carbamylated bovine serum mercaptalbumin. Biochem. 14, 1205-1210(1975)

8. Hearst, J. E.: Determination of the dominant factors which influence the net hydration of native sodium deoxyribonucleate. Biopolymers 3 , 57-68 (1965)

9. Hearst, J. E. \& C. W. SChmiD: Density gradient sedimentation equilibrium. In: C. H. W. Hirs \& S. N. Timasheff, eds., Methods in Enzymology, Vol. 27, Part D, pp. 111-127, Academic Press (New York) (1973)

10. Hearst, J. E. \& J. Vinograd: A three-component theory of sedimentation equilibrium in a density gradient. Proc. Natl. Acad. Sci. U.S. 47, 999-1004 (1961)

11. IFFT, J. B.: Proteins at sedimentation equilibrium in density gradients. In: P. Alexander \& H. P. Lundgren, eds., A Laboratory Manual of Analytical Methods of Protein Chemistry, Vol. 5, Chapter 4, pp. 151-223. Pergamon Press (New York) (1969)

12. IfFT, J. B.: The buoyant titration of native and carbamylated ovalbumin. Compt. Rend. Trav. Lab. Carlsberg 38, 315-338 (1971)

13. IfFT, J. B.: Proteins in density gradients at sedimentation equilibrium. In: C. H. W. Hirs and S. N. Timasheff, eds., Methods in Enzymology,
Vol. XXVII, Chapter 7, pp. 128-140 Academic Press (New York) (1973)

14. IFFT, J. B.: Sedimentation equilibrium of proteins in density gradients. In: N. Catsimpoolas, ed., Methods of Protein Separation: A Modern Survey, Vol. 1, pp. 193-237 Plenum (New York) (1975)

15. IFFT, J. B.: Sedimentation equilibrium of proteins in density gradients. Biophys. Chem. 5, 137-157 (1976)

16. IfFT, J. B., W. R. Martin III \& K. Kinzie: Density gradient proportionality constants for a number of aqueous binary solutions. Biopolymers 9 , 597-614 (1970)

17. IfFT, J. B. \& J. VINOGRAD: The buoyant behavior of bovine serum mercaptalbumin in salt solutions at equilibrium in the ultracentrifuge. II. Net hydration, ion binding, and solvated molecular weight in various salt solutions. J. Phys. Chem. 70, 2814-2822 (1966)

18. Pedersen, T. G. and J. B. IfFt: The buoyant titration of ovalbumin in four alkali halides. Hydration and ion binding. Carlsberg Res. Commun. 43, 65-76 (1978)

19. Pedersen, T. G., L. Sejersen \& J. B. Ifft: The partial molar volumes of six alkali halides and their ions as a function of concentration. Carlsberg Res. Commun. 42, 211-224 (1977)

20. ReIsler, E., Y. HAIK \& H. EIsenberg: Bovine serum albumin in aqueous guanidine hydrochloride solutions. Preferential and absolute interactions and comparison with other systems. Biochem. 16, 197-203 (1977)

21. Robinson, R. \& R. H. Stokes: Electrolyte solutions. Academic Press, p. 485 (New York) (1955)

22. RUARK, John E. \& J. B. IFFT: The buoyant and potentiometric titrations of human immunogamma globulin. Biopolymers 14, 1161-1171 (1975)

23. Sharp, D. S., R. Almassy, L. G. Lum, K. Kinzie, J. S. V. Zll \& J. B. IFFT: Buoyant and potentiometric titrations of synthetic polypeptides. II. Five copolypeptides and two ionionizable homopolypeptides in $\mathrm{CsCl}$ solutions. Biopolymers 15, 757-783 (1976)

24. Sharp, D. S. \& J. B. IfFT: An improved method of computation of density distributions. Biopolymers 16, 1153-1158 (1977)

25. Sharp, D. S., N. Fujita, K. Kinzie \& J. B. IfFT: Compressibility studies of three proteins in $\mathrm{CsCl}$ solutions in the analytical ultracentrifuge. Biopolymers (In press)

26. SVEndSEN, 1. Buoyant titration of bovine mer- 


\section{J. B. IfFT et al.: Buoyant titrations of polypeptides}

captalbumin chemically modified at the carboxyl groups. Carlsberg Res. Commun. 41, 111-120 (1976)

27. Williams, A. E. \& J. B. IfFT: The buoyant titration of bovine serum mercaptalbumin I. An interpretation in terms of ion binding. Biochim. Biophys. Acta. 181, 311 -318 (1969)

28. Williams, J. W., K. E. Van Holde, R. L. BALDWIN \& H. Furta: The theory of sedimentation analysis. Chem. Rev, 58, 715-806 (1958) 